\title{
TECNOLOGIAS NA ESCRITURA: uma experiência com professoras
}

Karla Rosane do Amaral Demoly ${ }^{1}$ (Doutoranda em Informática na Educação no PPGIE/UFRGS - e-mail: karla.demoly@unijui.edu.br)

Cleci Maraschin (Doutora em Educação pela UFRGS, Professora nos Programas PPGIE/UFRGS e PPGPSI/UFRGS - e-mail: clecimar@ orion.ufrgs.br)

Margarete Axt (Doutora em Educação pela UFRGS, Professora nos Programas PPGIE/UFRGS e PPGEDU/UFRGS - e-mail: maaxt@ufrgs.br)

\section{Resumo}

Neste estudo procuramos analisar como um grupo de professoras com condições perceptivas diferentes produzem uma escrita na convergência de mídias. Nossa hipótese é de que as práticas de composição escrita na Internet produz novas e inusitadas coordenações de ações, novos modos de escrever. A recursividade constitutiva entre escrita e tecnologia é descrita por vários autores, demonstrando que as tecnologias se transformam em ferramentas constitutivas de modos de pensar $e$ conhecer. Uma escrita que se faz no acoplamento com tecnologias digitais produz uma convergência interativa na qual existe grandes possibilidades de interlocução entre pessoas com diferentes condições perceptivas, pois mudam os modos sensorio-motores de acoplamento com a escrita e as coordenações de ações na rede de conversações escritas tecidas pelas professoras.

Palavras-chave: escrita, tecnologias, diferenças, acoplamento tecnológico.

\section{Technologies in writing: an experience with teachers}

\begin{abstract}
In this study we seek to analyze how a group of teachers, with different perceptive conditions, produce writings on the convergence of medias. Our hypothesis is that the practicing of written compositions on the Internet produces new and unusual coordination of actions, new methods of writing. Many authors describe the constitutive recursiveness between writing and technology, demonstrating that technologies are transformed into tools that constitute modes of thinking and knowing. A writing that is performed in the coupling of digital technologies produces an interactive convergence in which there are great possibilities of dialogue among people with different perceptive conditions, since they change sensory-motor modes of coupling with the act of writing and the coordination of actions on the net of written conversations woven by teachers.
\end{abstract}

Keywords: writing, technologies, differences, technological coupling.

\section{Introdução}

Esta pesquisa se origina de uma experiência de formação de alfabetizadoras e de uma necessidade de compreendermos as transformações nos modos de escrever dessas professoras quando encontram dispositivos tecnológicos.

\footnotetext{
${ }^{1}$ Realizou período de doutorado sandwich como Bolsista CAPES/PDEE na EHESS - École des Hautes Études en Sciences Sociales - Paris, sendo acolhida pela Professora Dra. Béatrice Fraenkel que coordena no LAHIC "Laboratoire d'anthropologie et d'histoire de l'institution de la culture" o grupo de pesquisa "Antropologia da Escritura". 
Durante cerca de 3 anos, um grupo de professoras do estado do Rio Grande do Sul se encontra regularmente com uma das autoras deste texto para refletir sobre os fazeres na escola. Dentre elas, quatro ensinam crianças em escolas regulares e três se envolvem em projetos com estudantes que apresentam surdez ou ausência de visão.

Durante esses encontros, as professoras manifestaram interesse de fazer uma produção escrita com vistas a dar visibilidade ao trabalho que realizam. Propusemos que construíssem esta escrita na forma de um hiperdocumento ${ }^{2}$, o que foi acolhido como um desafio e oportunidade de novas aprendizagens.

Acompanhar essa experiência nos levou a formular o seguinte problema de pesquisa: - Que deslocamentos e transformações nos modos de escrever de professoras encarregadas do ensino da escrita são passíveis de observação, quando engajadas na produção coletiva de um hiperdocumento na qual existe a possibilidade de conexão entre as mídias? Nossa hipótese é que a escrita acoplada à informática modifica os modos de escrever e o exercício de autoria, porque altera as coordenações de ações que as sustentam. Desde coordenações sensório-motoras como o teclar, a pilotagem do mouse; quanto coordenações significantes, entre representações alfabéticas, ideográficas e sonoras; bem como uma coordenação das relações entre os que se propõem a uma escrita coletiva, como é o caso do presente texto.

\section{Conectando tecnologias e professoras}

A organização das professoras para a produção do hiperdocumento marca o início de nosso estudo. Duas delas se distinguem, devido às suas condições perceptivas, no modo como operam com o conhecimento. ${ }^{3}$

Carlise, devido à perda de visão aos quatorze anos, utiliza até o início da pesquisa o sistema Braile mediante alguns suportes: reglete, punção e máquina de escrever Braile. O mesmo não ocorre com Angelisa que é surda, utiliza a Língua de Sinais para a comunicação face a face e escreve com caracteres alfabéticos.

Outra sua modalidade, as Línguas de sinais (LS), línguas naturais dos surdos têm a particularidade de não ter jamais desenvolvido uma forma escrita, no sentido onde as escrituras históricas têm adotado as línguas ditas "orais". (Garcia, 2005, p. 167, tradução das autoras).

Dois espaços de escritura se organizam neste estudo: a produção do hiperdocumento propriamente dito e outro, que denominamos de matético ${ }^{4}$ no qual escreviam sobre a experiência de escrever um hiperdocumento. Caracterizava-se então como uma escrita que se dobrava em si mesma. As conversações escritas (ANIS, 2005) se desenvolveram em fóruns e bate-papos durante o percurso de produção, em um ambiente informático de apoio a produção do hiperdocumento - TelEduc ${ }^{5}$.

A ausência de visão leva Carlise a utilizar os programas informáticos "Jaws" e o "Virtual Vision 5.0". São programas que realizam a conversão do texto em som. Quando utiliza o teclado, ela pode escutar o som das letras, sílabas, frases ou textos; segundo comandos utilizados.

\footnotetext{
${ }^{2}$ Um hiperdocumento se produz como uma escrita que nesta pesquisa se faz coletivamente e que considera como elementos os textos, mas também as imagens e os sons. Este termo estende a noção de hipertexto porque pode congregar a presença de vídeos e de animações.

${ }^{3}$ Utilizamos os nomes das professoras participantes da experiência por envolver uma escritura como exercício de autoria, sendo que este modo de designação foi devidamente autorizado e escolhido pelas professoras.

${ }^{4}$ Esse termo "matético" foi inspirado nos estudos de Seymour Papert, (1988), no qual ele fala dos diferentes modos de aprender, seria um aprender sobre o aprender. Neste estudo trazemos um escrever sobre o escrever.

${ }^{5}$ TelEduc é um ambiente de ensino à distância. Foi desenvolvido pelo Centro de Informática para a Educação (Nied) e Instituto de Informática (IC) da Universidade de Campinas (Unicamp).

V. 6 № 1, Julho, 2008
} 
A vontade de conhecer um programa que busca a criação de um espaço de escrita em Língua de Sinais leva as professoras a interagirem com o programa "Sign Writing". Para além de programas de edição de texto, as professoras passam a trabalhar com edição de vídeos, imagens e sons. Seguindo na trilha que nos sugere Varela (1999), procuramos observar as perguntas que elas se faziam e para onde estas perguntas apontavam, tomando como campo empírico o ambiente matético.

As professoras escrevem preponderantemente sobre alguns dos deslocamentos que eram sentidos como descontinuidades diante de suas experiências anteriores. Em um primeiro momento, comparavam esse modo de escrever com a forma como a escola ensina. Outro tema bastante discutido foi sobre a experiência de escrever com pessoas com diferentes condições perceptivas. Recortamos para este artigo algumas escritas no intuito de trazer à discussão algumas mudanças nas coordenações de ações que esta experiência de escrita coletiva oportunizou às professoras, frente a essas duas temáticas.

\subsection{Deslocamentos nos modos de escrever de professoras em contexto informático}

Escolhemos alguns extratos da conversação no Teleduc com o objetivo de flagrar indicadores de deslocamentos nos modos de escrever, identificando - como é nossa hipótese - alteração nas coordenações de ações realizadas.

Claudenir começa nos contando sobre o modo como esta experiência se deu na escola, momento em que o escrever esteve bastante associado ao medo de errar. Mesmo a partir de uma experiência difícil em relação à escrita, esta professora abre espaço na escola para que o escrever seja vivido com prazer pelas crianças.

Escrever é muito difícil, quando escrevo tenho, sempre, a sensação de que está errado. Tenho certeza que é devido a forma em que fui alfabetizada e em toda a minha trajetória escolar. $O$ acerto e o erro acompanhavam tudo que envolvia a escrita. Hoje tenho conciência, $e$ tenho tentado superar. Estimulo meus alunos a escrever e que esta escrita seja de forma prazerosa.

Extrato 1. Claudenir, 25/10/2005 .

Mais adiante, ao escrever sobre a experiencia de interagir com as colegas na Internet, aponta alguns deslocamentos nas coordenações de ações, quando o trabalho com elementos outros que não apenas textuais promove maior engajamento no escrever.

Colegas, estou fascinada com as novas descobertas, coisas simples que até então eu desconhecia, como usar o teclado, não apenas para digitação, mas a forma de copiar, colar... Estou conseguindo criar diversas atividades, que contribuem no desenvolvimento dos meus alunos. Outro dia encontrei uma história onde aparecia o desenho animando com o som das falas dos personagens, mas o que achei mais interessante é que estava escrito em letra palito e conforme os personagens iam falando, o texto mudava de cor. Já pensou como ficariam as crianças vendo tantas coisas diferentes?

Extrato 2. Claudenir, 23/11/2005.

\footnotetext{
${ }^{6}$ Sign Writing é um sistema computacional criado inicialmente por Valerie Sutton em 1974, a partir de um trabalho de invenção de um sistema para escrever danças que despertou a curiosidade dos pesquisadores da língua de sinais dinamarquesa que estavam procurando uma forma de escrever os sinais. Destaca-se no Brasil o trabalho dos pesquisadores Antönio Carlos da Rocha Costa e Marianne Stumpf que investem na ampliação do uso deste sistema pelos Surdos.

${ }^{7}$ Os extratos de escritas numerados de 1 à 7 foram retirados dos fóruns criados no ambiente TelEduc de apoio à pesquisa.

V. 6 № 1 , Julho, 2008
} 
A professora se mostra maravilhada com a possibilidade de realizar coordenações inusitadas de ações tais como as de copiar-colar imagens e textos. Utilizar um teclado para realizar funções e não somente para digitar é também uma nova experiência de ação. Coordenar em uma escrita movimento e sons; editar imagens e transformá-las, escolher a tonalidade das cores, os melhores ângulos e disposições dos elementos na tela. Um escrever sobre o escrever potencializa um outro tipo de coordenação de ação pouco exercitável em modos de escrever não coletivos; que consiste em um retorno a escrita em outras escritas próprias e dos colegas, como podemos distinguir nesta escrita de Inês:

Refiro-me ao que posso escrever, agora aqui com vocês, daqui a instantes pode ser transformado, ou seja, a oportunidade de escrever interagindo com o outro faz com que a mudança aconteça rapidamente.

Extrato 3. Inês, 11/07/2006.

Pensamos que esta escritura escolarizada é entendida como experiência individual - competência individual - focada em aspectos outros que não a possibilidade de « conversar », tecer versos com outros na forma da escrita, com autores-amigos através da leitura, consigo mesmo através da reflexão, processos que constituem diferentes percursos de escritura. A escrita de Sandra nos oportuniza observar este processo no escrever:

Fico pensando, ao ver as afirmações em que buscam fazer da escrita momentos de prazer... Como vocês acreditam que possamos buscar o prazer na construção textual vindas de uma formação repressora e punitiva? Qual seria o nosso caminho de transformação? Pois quando começo a escrever textos, artigos, a tensão fica me acompanhando.

Extrato 4. Sandra B., 25/05/2006.

Outros sistemas de escrita, línguas e trajetórias estão presentes neste estudo. Carlise nos aporta suas experiências com a escrita em uma circunstância em que uma doença provoca a perda da visão. Esse acontecimento em sua vida faz com que a leitura só seja possível através da constituição de outras coordenações de ações (um outro para ler, dispositivos em braille, ampliação e reforço das letras)

Desde criança eu sempre gostei muito de escrever e ler, mas sempre tive dificuldades pra ler quando enxergava por causa da minha baixa visão. E depois que eu perdi a visão, eu não podia ler muito, apesar do meu grande gosto pela mesma, por causa da falta de livros em braile e da disponibilidade, da necessidade de outras pessoas auxiliarem então na leitura dos livros. Sempre foi complicado e difícil, porque com a baixa visão não é fácil estudar, porque as professoras não estão preparadas para auxiliar a gente a superar as dificuldades da gente. (...) Aí, muitas vezes eu ia mal em matemática, porque eu trocava os números, eu achava que eu via uma coisa e era outra.

Extrato 5. Carlise, 21/06/2005. 
Esta professora, mesmo diante do grave descuido da escola em relação às suas condições perceptivas, sustenta o prazer e a vontade de escrever e de ler. Poderemos observar mais adiante a participação de Carlise em situação de escrita na Internet com suporte de programas informáticos específicos para suas necessidades. Destacamos uma dentre suas interferências nos fóruns:

Recentemente percebi que a comunicação entre surdos e cegos não é impossível, pois com o auxílio de tecnologias como o Jaws e o Virtual Vision 5.0 posso ler as mensagens enviadas aos surdos, por exemplo, via MSN, e respondê-las. Essas tecnologias são possibilitadoras da construção de um ambiente neutro, onde as diferenças sensoriais são diluídas pelas adaptações que as mesmas oferecem para a melhor comunicação entre usuários com necessidades distintas.

Extrato 6. Carlise, 04/06/2006

Carlise indica que a escrita digital possibilita conversação e produção entre pessoas que tecem suas vidas em meio à diferentes condições perceptivas, ou seja, permite constituir outras coordenações de ações inusitadas em sua experiência anterior e, como propõe nossa hipótese, se mudam as coordenações de ações, mudam os modos de escrever.

A escritura a partir do Jaws ou do Virtual Vision 5.0 exige a memorização de diferentes comandos para que, ao teclar, se possa escutar as letras, as palavras, as frases, os parágrafos ou mesmo o texto. A correção dos erros ortográficos exige atenção à leitura realizada através da escuta dos sons e, esta exigência de memorização, mostra-se mais presente no viver de Carlise.

Gostaria de dizer que aos poucos estou me apropriando desta tecnologia importante, que é o computador e todos os recursos que o mesmo disponibiliza. Está sendo um processo lento, mas gratificante à medida que vou adquirindo mais autonomia e liberdade para acessá-lo e escrever. No início, pela não adaptação ao computador, era difícil trabalhar no mesmo. Agora, com a ajuda do Jaws e de algumas explicações, estou podendo engatinhar com um pouco mais de facilidade dentro do mundo virtual. A expressão de nossas idéias e pensamentos e consequentemente a reflexão de questões em conjunto através de debates sobre nossas inquietações é um dos grandes benefícios, também, trazidos por essa tecnologia.

Extrato 7. Carlise, 09/07/2006.

As trocas escritas entre pessoas com diferentes condições perceptivas ganha importância e espaço nos fóruns e salas de Bate-Papo. Angelisa observa que produz algo com colegas não surdas e com Carlise que é cega. Esta professora se interroga de modo recorrente nos fóruns e bate-papos sobre se será mesmo possível construir uma escritura com pessoas não surdas. Sua questão decorre das coordenações de ações vividas, se pergunta se é possível construir outras relações, inusitadas, impensáveis em sua experiência.

Brigitte Garcia é uma pesquisadora que se dedica ao estudo da possibilidade de formalização gráfica da Língua de Sinais Francesa e nos remete aos múltiplos elementos em jogo neste trabalho. 
O olhar aqui jogando um papel determinante - ele é ao mesmo tempo condição de troca semiótica e vetor da inscrição em tal ou tal gênero discursivo -, estas línguas são assim, fundamentalmente, línguas do face-à-face, ainda que os locutores destas "línguas sem território" são também, geralmente, cidadãos de sociedades estruturadas pelo escrito. (Garcia, 2005, p. 167, tradução das autoras)

Angelisa experiencia em Salas de Bate-Papo processos de conversação escrita em um momento importante para o coletivo, logo após ter inserido no ambiente alguns escritos sobre a LS e Carlise ter iniciado pela primeira vez em sua vida um trabalho em fotografia:

(09:49:18) Carlise: Angelisa, fiquei feliz por teres vindo.

(09:49:41) angelisa: eu posso interação colega

(09:50:09) Carlise: Angelisa, eu tirei fotos hoje, depois pode ver no meu portfólio, amanhã.

(09:50:32) angelisa: eu posso ver fotos Carlise

(09:51:03) Claudenir: é muito legal participar deste momento de troca de ideias

(09:51:47) angelisa: claudenir, eu entender o que tu escrever

(09:51:55) sandra bucholz: estou muito curiosa para ver como ficaram suas fotos, acredito que ficaram ótimas pois tem muita sensibilidade e, se cortou minha cabeça eu não ficarei triste, pelo contrário, sei que estou lá.

Extrato 8. Conversação escrita em sala de bate-papo, 25/03/2006.

Observamos que as ações de escrita no ciberespaço operam esta transformação, quando Angelisa e as professoras passam a observar o próprio fazer e se dão conta de que é possível estabelecerem redes de conversações escritas nas quais experiências inusitadas podem ser efetivadas.

(09:52:12) angelisa: Coloquei material para aprender escrever LIBRAS.

(10:03:24) angelisa: Teu material, assunto, escrita Libras, aprender. (10:03:24) angelisa: carlise interaçao conversando com me

(10:04:06) Carlise: Vamos cada uma escrever o que quer fazer agora?

(10:04:59)Carlise: Eu escreverei sobre Braile e material Braile, depois sobre a informática para cegos

(10:05:36) angelisa: carlise, eu acho literatura de LIBRAS ou outro;

(10:05:56) Claudenir: gostaria de construir jogos e atividades.

(10:06:30) angelisa: claudenir,pergunto vc acho sentir contato comunicação conversando carlise e eu?

(10:06:43)Claudenir fala para Todos: Sim Angelisa, eu entendo tudo, podemos continuar...

(10:07:07) angelisa fala para Todos: claudenir legal.

Extrato $n^{\circ}$ 9. Conversação escrita em sala de bate-papo, 25/03/2006.

Angelisa e Carlise se transformam, ao longo da experiência, em colegas que portam saberes diferentes e modos de fazer a escrita antes desconhecidos. 


\section{0 escrever como uma dança ${ }^{8}$ recursiva em uma rede de conversações}

O escrever não se traduz simplesmente em um manejo de um sistema de códigos que serve para representar uma realidade independente do observador. Tomamos a escrita como um modo particular de linguajar, ou seja, uma experiência do viver em um domínio específico que se produz em redes de conversação. (Maturana, 2004, p. 142).

As redes de conversação nas quais configuramos nosso viver são tecidas como um conjunto de condutas coordenadas com os outros através de múltiplas formas de linguagem. Coordenar coordenações de coordenações condutuais implica em atualizar a recursão. A cada retorno, pode ser produzida uma pequena diferença capaz de, em uma seqüência histórica de recursões, transformar a estrutura do viver e, por decorrência, suas produções. Ou seja, tornar possível a criação deslocando as coordenações de ações. Se isso acontece, já acontece no transcurso da história de uma rede de conversação. Esse processo é mais afetado quando essa rede se acopla a outras ferramentas (suportes, interfaces, mecanismos) comunicativas.

Os trabalhos de Derrida (1967, 2001), Marques (1999) e Goody (1979) mostraram que, ao contrário do que podemos pensar comumente, modos de pensamento e de conhecimento se configuram a partir dos usos que fazemos das tecnologias as quais nos acoplamos no linguajar.

\section{Conclusão}

A escrita coletiva das professoras em dispositivos informáticos produziram coordenações de ações que perturbam e transformam a própria estrutura da ação de escrever, na direção de maior implicação de pessoas que antes não se imaginavam produzindo algo juntas.

A análise de extratos do escrever sobre o escrever permitiu observar como as escritas das professoras revelam mudanças em determinadas coordenações de ações, na problematização de algumas coordenações já estabelecidas e na abertura a novas experiências de escrita, quando interagem com ferramentas informáticas e quando são capazer de produzir com a diferença e não apesar dela.

O espaço matético de escrita - os espaços nos quais as professoras escreviam sobre o escrever - surge vinculado à possibilidade de novas experiências, muito ricas, a ponto de contribuir com uma conversação que faz perguntar: se é possível conversar com cegos, não ouvintes e, ao perguntar, já estão conversando.

$\mathrm{O}$ escrever no acoplamento com tecnologias informáticas, ao favorecer uma produção que envolve além dos textos, imagens e sons, cria as condições para o escrever coletivo entre professoras (ouvintes/surdas, cegas/não cegas).

Novamente enfatizamos, um escrever que se faz com as diferenças (onde a diferença enriquece o coletivo) e não apesar da diferença (onde a diferença deve ser « superada », «nivelada » na tentativa de constituição de uma homogeneidade.

\footnotetext{
${ }^{8} \mathrm{O}$ termo dança tem aqui um sentido metafórico que utilizamos para nos referirmos aos movimentos do escrever neste entrelaçamento em que um emocionar ou outro vai delineando o que nos mostra uma escrita. $\mathrm{O}$ que se passa entre duas ou mais pessoas no interatuar da escrita é uma dança porque vão se transformando no fazer, sem que uma programação prévia possa dar conta do que produzirão. Referimos à uma experiência de olhar para as perguntas que se fazem e de valorização das circunstâncias do viver que as fazem, juntas, escrever.
} 
Atualmente dispomos de sistemas computacionais que favorecem a emergência de um diálogo escrito entre pessoas com diferentes histórias de escritas, tal como o diálogo mostrado nos extratos $\mathrm{n}^{\circ} \mathrm{s}(6,7,8$ e 9$)$ no qual pessoas alfabetizadas em uma escrita alfabética, ou em Língua de Sinais ou em Braile possam conversar. São novas coordenações em construção. Através dos extratos $n^{\circ} \mathrm{s}(1,2,3,4,5)$ podemos observar que as professoras se interrogam sobre um modo de escrever escolarizado, quando se vêem na experiência diante de outro modo de escrever que se produz pela implicação e encontro com outros que têm interesses comuns.

Pensamos que os estudos sobre o escrever e as tecnologias que suportam esta produção tornam-se cada vez mais importantes em nosso contexto. Existe uma nova possibilidade de produção de escrituras na convergência de mídias na medida em que podemos reconhecer como legítimas as formas de escritura, os sistemas e línguas diferentes utilizados para viver e conhecer.

\section{Referências Bibliográficas}

ANIS, Jacques; ZARA, Alessandro. L'ordinateur support textuel ? Le texte informatique comme processus. L'écriture entre support et surface. Paris: L'Harmattan, 2005, p. 71-85.

DERRIDA, Jacques. De la grammatologie. Paris: Les éditions de Minuit, 1967.

Papier Machine. Paris: Galilée, 2001.

FREEDOMSCIENTIFIC. Jaws. Disponível em: <http://www.freedomscientific.com>. Acesso em 03 de jun. 2008.

GARCIA, Brigitte. Une dimension de trop pour l'écriture ? Questions posé à la surface pour la formalisation graphique de langue des signes. L'écriture entre support et surface, Paris : L'Harmattan, 2005p. 167-180.

GOODY, Jack. La raison graphique: la domestication de la pensée sauvage, Paris: Les éditions de Minuit, 1979.

MARQUES, Mário Osório. Escrever é preciso: o princípio da pesquisa. Ijuí: UNIJUI, 1999.

MATURANA, Humberto; POÖRKSEN, Bernhard. Del ser al hacer: los orígenes de la biología del conocer. Santiago: J-C-Sáez editor, 2004.

MICRO POWER. Virtual Vision Disponível em: <http://www.micropower.com.br/>. Acesso em 18 mar. 2008.

PAPERT, Seymour. Logo: computadores e educação. São Paulo: Brasiliense, 1985.

SIGNWRITING. Sign Writing Site. Disponível em: <http://www.signwriting.org/read.html>. Acesso em 05 de jan. 2008.

UNICAMP, Nied, TelEduc. Disponível em: < http://teleduc.nied.unicamp.br/pagina/ >, Acesso em 10 jan. 2007.

VARELA, F. El fenómeno de la vida. Santiago: Dolmen, 1999. 